\title{
Impact of different periodontitis case definitions on periodontal research
}

\author{
Fernando O. Costa ${ }^{1)}$, Alessandra N. Guimarães ${ }^{1)}$, Luís O. M. Cota ${ }^{1)}$, \\ André L. Pataro ${ }^{1)}$, Takeshi K. Segundo ${ }^{1)}$, Sheila C. Cortelli ${ }^{2)}$ and José E. Costa ${ }^{1)}$ \\ ${ }^{1)}$ Department of Periodontology, Dentistry School, Federal University of Minas Gerais, Belo Horizonte, Brazil \\ ${ }^{2)}$ Department of Dentistry, Periodontics Research Division, University of Taubaté, Taubaté, São Paulo, Brazil
}

(Received 25 October 2008 and accepted 19 February 2009)

\begin{abstract}
Different periodontitis definitions have been used in periodontal research. This study assessed the impact of case definition on the prevalence and extent rates of periodontitis. A data set including 340 periodontal records, collected in Belo Horizonte, Brazil, was used. Periodontitis was defined as: 1 ) one site with probing depth $(\mathrm{PD}) \geq 4 \mathrm{~mm} ; 2$ ) clinical attachment level $(\mathrm{CAL}) \geq 5 \mathrm{~mm}$ in $\geq 4$ sites + one site with $P D \geq 4 \mathrm{~mm}$; 3) $\mathrm{CAL} \geq 6 \mathrm{~mm}$ in $\geq 2$ teeth + one site with $\mathrm{PD} \geq 5 \mathrm{~mm}$; 4) $\geq 4$ teeth with $\geq 1$ sites with $P D \geq 4 \mathrm{~mm}+$ CAL $\geq 3$ $\mathrm{mm}$; 5a) interproximal CAL or $\mathrm{PD} \geq 4 \mathrm{~mm}$ at $\geq 2$ sites, not on the same tooth; and 5b) interproximal CAL of $\geq 6 \mathrm{~mm}$ at $\geq 2$ sites, not on the same tooth $+P D \geq 5 \mathrm{~mm}$ at $\geq 1$ proximal site. Definition 5 was determined to be the gold standard and the definitions were compared by means of agreement, sensitivity, specificity, and positive and negative predictive values. Prevalence and extent rates greatly varied, from $13.8 \%$ to $65.3 \%$ and from $9.7 \%$ to $55.6 \%$, respectively. The use of different case definitions has a great impact on the prevalence and extent rates of periodontitis. (J Oral Sci 51, 199. 206, 2009)
\end{abstract}

Keywords: diagnostic criteria; epidemiology; extent; periodontitis; prevalence.

Correspondence to Dr. Fernando Oliveira Costa, Federal University of Minas Gerais, Department of Dental Clinics, Oral Surgery and Oral Pathology, Antonio Carlos Avenue, 6627, Pampulha, PO Box 359, Zip Code 31270-901, Belo Horizonte, MG, Brazil

Tel: +55-31-3499-2412 ext 2427

Fax: +55-31-3282-6787

E-mail: focperio@uol.com.br

\section{Introduction}

A large number of epidemiological studies in periodontology have demonstrated different rates of prevalence, severity, and extent of periodontitis among distinct populations (1-8). This difference in periodontitis estimates may be directly related to incongruities in the methodologies of data collection and case definitions adopted in periodontal research. Case definition of periodontitis is a fundamental requirement for populationbased surveillance of the disease. However, an agreement of such definition criteria has not yet been established (915). Any measurement of prevalence or frequency of periodontitis is dependent on how the disease is defined; that is, the case definition. Diagnostic criteria proposed in dental literature use different thresholds to define the number of affected teeth, the clinical levels of gingival inflammation, and the clinical attachment level (9,15-19).

Therefore, a number of clinical risk indicators have been used for periodontitis case definition, including bleeding on probing, redness, suppuration, probing depth (PD), tooth mobility, clinical attachment level (CAL), and bone loss. However, only the latter two parameters cited can be consistently associated with periodontitis, as they describe destructive components related to the disease (15). In epidemiologic research of periodontal diseases, case definitions are crucial since they can affect the internal and external validity as well as conclusions reached by the study. In addition, they can seriously affect the comparisons among the results of other studies. One important aspect of this issue refers to the possibility of inducing over or underestimation of periodontal treatment needs $(9,15,20)$. Although several studies assumed their own periodontitis 
case definitions by adopting different clinical indicators of severity and extent, in general including measurements of PD, CAL, and the extent of bone loss, a lack of standardization and conflicts of definition can still be observed. Another important aspect concerning case definition is related to the ordinal threshold value for PD and/or CAL to determine true evidence of the destructive process in the periodontal site as well as the number of sites affected by that threshold necessary to establish the presence of the disease. This lack of uniformity comes across as a consequence of different diagnostic criteria with distinct cut off points for periodontitis definitions $(2,10,15,21)$.

In this manner, periodontal research has been biased by difficulties in disease description, diagnosis, and score designation for clinical manifestations of periodontitis. Regardless of the study design, be it experimental or observational, the clinical entity under investigation needs to be defined in such a way that subjects or sites can be consistently categorized as affected or unaffected by the disease. Without a clear definition of the case, results and associations can be seriously impaired and brought into question (22). Therefore, the aim of the present study was to evaluate the impact of five different case definitions on the prevalence and extent rates of periodontitis as well as to determine the agreement and validity among such definitions.

\section{Materials and Methods}

\section{Sampling strategy}

Subjects were selected from a list of 1,720 patients awaiting dental treatment at the municipal public health service of the west region of Belo Horizonte City, Brazil from 2003 to 2005. The inclusion criteria included good systemic health, age ranging from $30-45$ years, and no antibiotic use within 3 months prior to the examination. Sample size calculation was performed using statistical software (Epi info, version 4.0), based on a periodontitis prevalence rate of $30 \%$. It was calculated according to the 95\% confidence interval of these prevalence data and a power test estimation of $80 \%$, adopting a variation of $5 \%$ around the prevalence rate. In this manner, after having applied the inclusion criteria, a data set including 340 periodontal records was randomly selected and used in the present study. The study sample comprised of subjects of both genders, of multiethinic groups, and of low socioeconomic and low education levels.

After obtaining written informed consent, subjects were asked about their medical history and demographic data. A clinical periodontal examination was then performed, and subjects presenting with specific periodontal treatment needs were referred to specialized dental public units for dental treatment.

The present study was approved by the Federal University of Minas Gerais Research Ethics Committee (COEPUFMG).

\section{Periodontal clinical examination}

Circumferential periodontal probing was manually performed with a University of North Carolina (UNC)-15 periodontal probe (Hu Friedy, Chicago, IL, USA) at the mesial, buccal, distal, and lingual sites of each tooth. Measurements of probing depth from the gingival margin and measurements of clinical attachment level from the cementoenamel junction were subsequently recorded. Interproximal sites were examined on buccal and lingual sides, and the highest measurement was recorded. In an attempt to minimize errors during the periodontal probing process, some exclusion criteria were adopted: third molars; teeth presenting unsatisfactory restorations, extensive caries lesions, or fractures; teeth where the cementoenamel junction could not be properly determined; and areas presenting great gingival morphological alterations (23).

All measurements were performed by one trained and calibrated periodontist. As part of the calibration process, periodontal examinations were repeated in $10 \%$ of the sample within 14 days and intraexaminer reliability scores were tested. Unweighted kappa (k) scores, for values lower and higher than $4 \mathrm{~mm}$, were 0.81 for PD and 0.79 for CAL. An intraclass correlation coefficient of 0.79 was also attained.

\section{Diagnostic criteria for periodontitis definition}

Five periodontitis case definitions, summarized in Table 1 , were adopted in the study. To determine the extent of periodontitis in each definition, the following classification was used: 1) localized form: presence of $\leq 30 \%$ of sites affected by the definition requirements of $\mathrm{PD}$ and/or CAL; or 2) generalized form: presence of $>30 \%$ of sites affected by the definition requirements of PD and/or CAL (9).

\section{Statistical analysis}

Data descriptive analysis was performed and prevalence rates of periodontitis (absolute and relative frequencies) for each definition were reported. Agreement among definitions was tested through an unweighted Kappa test. In addition, definition 5a was determined to be the gold standard, and the sensitivity (ST), specificity (SP), and positive (PPV) and negative (NPV) predictive values were calculated for each definition. Estimates were then compared among definitions. All analyses were performed using statistical software (STATA 9.0, Stata Corporation, 
Table 1 Different periodontitis case definitions

\begin{tabular}{|c|c|c|c|}
\hline \multirow{2}{*}{$\begin{array}{l}\text { Periodontitis } \\
\text { case definition }\end{array}$} & \multicolumn{3}{|c|}{ Requirements } \\
\hline & Clinical attachment level (CAL) & & $\begin{array}{l}\text { Probing depth } \\
\text { (PD) }\end{array}$ \\
\hline Definition 1 & & & at least 1 site with \\
\hline (Hujoel et al. 2006) & & & $\mathrm{PD} \geq 4 \mathrm{~mm}$ \\
\hline Definition 2 & 4 or more sites with & & at least 1 site with \\
\hline (Beck et al. 1990) & $\mathrm{CAL} \geq 5 \mathrm{~mm}$ & and & $\mathrm{PD} \geq 4 \mathrm{~mm}$ \\
\hline Definition 3 & 2 or more teeth with & and & 1 site with \\
\hline (Machtei, 1992) & $\mathrm{CAL} \geq 6 \mathrm{~mm}$ & and & $\mathrm{PD} \geq 5 \mathrm{~mm}$ \\
\hline $\begin{array}{l}\text { Definition } 4 \\
\text { (López et al. 2002) }\end{array}$ & $\begin{array}{l}4 \text { or more teeth with at least one site with } \\
\qquad \text { CAL } \geq 3 \mathrm{~mm}\end{array}$ & and & $\begin{array}{l}4 \text { or more teeth with at least one site with } \\
\qquad P D \geq 4 \mathrm{~mm}\end{array}$ \\
\hline $\begin{array}{l}\text { Definition 5a } \\
\text { (Page and Eke, 2007) }\end{array}$ & $\begin{array}{c}\geq 2 \text { sites with interproximal } \\
\text { CAL } \geq 4 \mathrm{~mm} \\
\text { not on the same tooth }\end{array}$ & or & $\begin{array}{c}\geq 2 \text { sites with interproximal } \\
P D \geq 4 \mathrm{~mm} \\
\text { not on the same tooth }\end{array}$ \\
\hline $\begin{array}{l}\text { Definition } 5 \mathrm{~b} \\
\text { (Page and Eke, 2007) }\end{array}$ & $\begin{array}{c}\geq 2 \text { sites with interproximal } \\
\text { CAL } \geq 6 \mathrm{~mm} \\
\text { not on the same tooth }\end{array}$ & and & $\begin{array}{l}\geq 1 \text { sites with interproximal } \\
\qquad \mathrm{PD} \geq 6 \mathrm{~mm}\end{array}$ \\
\hline
\end{tabular}

Table 2 Periodontal status of the sample: prevalence of affected sites with different thresholds for CAL and PD ( $n=340$ individuals; $n=7140$ sites)

\begin{tabular}{|c|c|c|c|c|c|c|c|c|}
\hline \multirow{2}{*}{$\begin{array}{l}\text { Periodontal } \\
\text { Parameters }\end{array}$} & \multicolumn{2}{|c|}{$\begin{array}{c}\text { Sites } \\
<3 \mathrm{~mm}\end{array}$} & \multicolumn{2}{|c|}{$\begin{array}{c}\text { Sites } \\
\geq 3 \leq 5 \mathrm{~mm}\end{array}$} & \multicolumn{2}{|c|}{$\begin{array}{c}\text { Sites } \\
>5<7 \mathrm{~mm} \\
\end{array}$} & \multicolumn{2}{|c|}{$\begin{array}{c}\text { Sites } \\
\geq 7 \mathrm{~mm}\end{array}$} \\
\hline & $n$ & $\begin{array}{c}\% \% \\
(95 \% \mathrm{CI}) \\
\end{array}$ & $n$ & $\begin{array}{c}\% \\
(95 \% \mathrm{CI}) \\
\end{array}$ & $n$ & $\begin{array}{c}\% \\
(95 \% \mathrm{CI}) \\
\end{array}$ & $n$ & $\begin{array}{c}\% \\
(95 \% \mathrm{Cl}) \\
\end{array}$ \\
\hline $\begin{array}{l}\text { Clinical } \\
\text { attachment level } \\
\text { (CAL) }\end{array}$ & 4737 & $\begin{array}{c}66.35 \\
(3.1-22.3)\end{array}$ & 1820 & $\begin{array}{c}25.49 \\
(18.2-50.3)\end{array}$ & 405 & $\begin{array}{c}5.67 \\
(4.9-11.8)\end{array}$ & 178 & $\begin{array}{c}2.49 \\
(1.8-5.3)\end{array}$ \\
\hline $\begin{array}{l}\text { Probing depth } \\
\text { (PD) }\end{array}$ & 4096 & $\begin{array}{c}57.37 \\
(15.7-20.8)\end{array}$ & 2180 & $\begin{array}{c}30.54 \\
(24.5-57.3)\end{array}$ & 643 & $\begin{array}{c}9.0 \\
(6.6-14.3)\end{array}$ & 221 & $\begin{array}{c}3.09 \\
(2.2-6.7)\end{array}$ \\
\hline
\end{tabular}

College Station, TX, USA).

\section{Results}

Of the 340 subjects, $172(50.6 \%)$ were males and 168 $(49.4 \%)$ were females. The subjects were of low socioeconomic status (family monthly income $\leq$ USD $\$ 300$ ) and low educational levels (average of $6.5 \pm 2.1$ years of formal education). The periodontal status of the sample is detailed in Table 2. Of the 7,140 sites evaluated, the proportions of CAL $\geq 3$ and $\leq 5 \mathrm{~mm},>5$ and $<7 \mathrm{~mm}$, and $\geq 7 \mathrm{~mm}$ were $25.4 \%, 5.6 \%$, and $2.5 \%$ respectively, while the proportions of $\mathrm{PD} \geq 3$ and $\leq 5 \mathrm{~mm},>5$ and $<7 \mathrm{~mm}$, and $\geq 7 \mathrm{~mm}$ were $30.5 \%, 9.0 \%$, and $3.1 \%$, respectively. Prevalence rates of periodontitis based on the cut off points of each definition are displayed in Fig. 1. It could be observed that frequencies of periodontitis for definition 1 , $2,3,4,5 \mathrm{a}$ and $5 \mathrm{~b}$ were $65.3 \%, 23.8 \%, 16.5 \%, 38.6 \%$, $41.2 \%$, and $13.8 \%$, respectively. Prevalence rates emerging from definition 2,3 , and $5 \mathrm{~b}$ were lower than those emerging from definition 1, 4, and 5a. Kappa scores (k) indicating agreement between definitions are displayed in Table 3 . Satisfactory agreement between definition 1 and $4(k=0.72$;

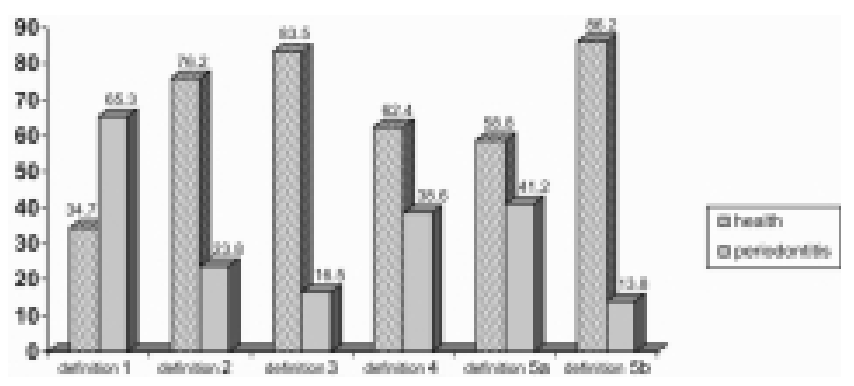

Fig. 1 Periodontal status (health and periodontitis) determined by case definitions (percent).

$95 \%$ CI $0.69-0.77), 1$ and $5 \mathrm{a}(\mathrm{k}=0.73 ; 95 \%$ CI $0.71-$ $0.79), 2$ and $3(\mathrm{k}=0.72 ; 95 \% \mathrm{CI} 0.68-0.75), 3$ and $5 \mathrm{~b}(\mathrm{k}$ $=0.69 ; 95 \%$ CI $0.61-0.74)$, and 4 and $5 \mathrm{a}(\mathrm{k}=0.71 ; 95 \%$ CI 0.68 - 0.76) were observed. Extent of periodontitis according to the definition adopted for localized and generalized forms is displayed in Fig. 2. A great variability among the criteria could be observed. Prevalence rates for localized periodontitis varied from $9.7 \%$ to $55.6 \%$, and generalized periodontitis from $4.1 \%$ to $11.0 \%$. When 
Table 3 Agreement among definitions [kappa coefficients (95\%CI)]

\begin{tabular}{lccccc}
\hline & Definition 1 & Definition 2 & Definition 3 & Definition 4 & Definition 5a \\
\hline Definition 2 & 0.28 & - & - & - & - \\
& $(0.17-0.31)$ & & & & \\
Definition 3 & 0.19 & 0.72 & - & - & - \\
& $(0.15-0.21)$ & $(0.68-0.75)$ & & & \\
Definition 4 & 0.72 & 0.39 & 0.29 & - & - \\
& $(0.69-0.77)$ & $(0.33-0.45)$ & $(0.23-0.34)$ & & - \\
Definition 5a & 0.73 & 0.37 & 0.35 & 0.71 & \\
& $(0.71-0.79)$ & $(0.32-0.45)$ & $(0.32-0.41)$ & $(0.68-0.76)$ & \\
Definition 5b & 0.17 & 0.62 & 0.69 & 0.27 & 0.52 \\
& $(0.15-0.21)$ & $(0.54-0.66)$ & $(0.61-0.74)$ & $(0.18-0.32)$ & $(0.49-0.61)$ \\
\hline
\end{tabular}

$P<0.001$ for all k coefficients

Table 4 Distribution of periodontitis and diagnostic values for different case definitions in comparison with definition 5a (gold standard)

\begin{tabular}{|c|c|c|c|c|c|c|}
\hline Definition & $\begin{array}{l}\text { Sensibility } \\
(95 \% \mathrm{CI})\end{array}$ & $\begin{array}{c}\text { Specificity } \\
(95 \% \mathrm{CI})\end{array}$ & $\begin{array}{c}\text { Positive } \\
\text { predictive } \\
\text { value } \\
(95 \% \mathrm{CI})\end{array}$ & $\begin{array}{c}\text { Negative } \\
\text { predictive } \\
\text { value } \\
(95 \% \mathrm{CI}) \\
\end{array}$ & $\begin{array}{l}\text { Prevalence of } \\
\text { periodontitis } \\
(n=340)\end{array}$ & $\begin{array}{c}\text { Number of } \\
\text { subjects } \\
\text { affected } \\
(n=340) \\
\end{array}$ \\
\hline Definition 1 & $\begin{array}{c}100 \% \\
(91.2-100)\end{array}$ & $\begin{array}{c}20.3 \% \\
(3.8-23.4)\end{array}$ & $\begin{array}{c}48 \% \\
(41.6-53.2)\end{array}$ & $\begin{array}{c}100 \% \\
(71.2-100)\end{array}$ & $65.3 \%$ & 222 \\
\hline Definition 2 & $\begin{array}{c}100 \% \\
(91.2-100)\end{array}$ & $\begin{array}{c}33.7 \% \\
(17.2-38.9)\end{array}$ & $\begin{array}{c}56.7 \% \\
(47.8-64.7)\end{array}$ & $\begin{array}{c}100 \% \\
(82.1-100)\end{array}$ & $23.8 \%$ & 81 \\
\hline Definnition 3 & $\begin{array}{c}100 \% \\
(91.2-100)\end{array}$ & $\begin{array}{c}7.5 \% \\
(4.3-11.2)\end{array}$ & $\begin{array}{c}21 \% \\
(17.8-26.7)\end{array}$ & $\begin{array}{c}100 \% \\
(72,8-1000\end{array}$ & $16.5 \%$ & 56 \\
\hline Definition 4 & $\begin{array}{c}100 \% \\
(91.2-100)\end{array}$ & $\begin{array}{c}88.3 \% \\
(73.5-91.2)\end{array}$ & $\begin{array}{c}92.9 \% \\
(78.1-95.7)\end{array}$ & $\begin{array}{c}100 \% \\
(91.5-100)\end{array}$ & $38.6 \%$ & 131 \\
\hline Definition $5 \mathrm{a}$ & - & - & - & - & $41.2 \%$ & 140 \\
\hline Definition $5 b$ & $\begin{array}{c}100 \% \\
(91.2-100)\end{array}$ & $\begin{array}{c}6.2 \% \\
(3.8-10.1)\end{array}$ & $\begin{array}{c}18.3 \% \\
(15.2-21.6)\end{array}$ & $\begin{array}{c}100 \% \\
(68.8-100)\end{array}$ & $13.8 \%$ & 47 \\
\hline
\end{tabular}

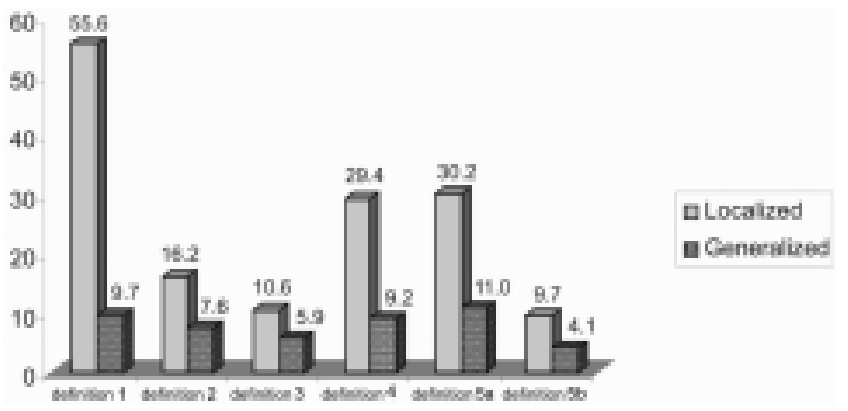

Fig. 2 Extent rates of localized and generalized forms of periodontitis according to different case definitions (percent). comparing all definitions to definition 5a, which was considered the gold standard, satisfactory ST and NPV were obtained. However, satisfactory SP and PPV were obtained only for definition 4 ( $\mathrm{SP}=88.3$; 95\% CI [73.5 - 91.2]; PPV $=92.9 ; 95 \%$ CI [78.1 - 95.7]). Values of SP and PPV for the definitions increased in the following sequence: $5 \mathrm{~b}, 3$, 1, 2, and 4. This order can be interpreted as an increase in the capacity of each definition to accurately identify subjects with and without periodontitis with regard to definition 5a (Table 4).

\section{Discussion}

Numerous epidemiological studies conducted in different 
populations have reported different prevalence rates of periodontitis. These differences can be attributed to two important aspects: 1) non-standardized definition of the disease, and 2) the influence of biological, social, and behavioral risk variables, particularly smoking, socioeconomic level, diabetes, age, ethnicity, and access to oral health services $(3,7,9,16,24)$. The present study showed that the differences in periodontitis prevalence rates related to case definition were largely significant: $65.3 \%$ (definition 1), $23.8 \%$ (definition 2), $16.5 \%$ (definition 3), $38.6 \%$ (definition 4), $41.2 \%$ (definition 5a), and $13.8 \%$ (definition $5 b)$.

It is important to note that these prevalence rates were not methodologically associated with risk variables. These variables greatly vary within the populations and directly interfere with the disease prevalence rates reported. The use of a cross-sectional data set of periodontal records in the present study, with no evaluation of risk variables, did not influence the comparisons and results, since all definitions were applied in the same data set. In addition, subjects in a restricted age range ( $30-45$ years) were included to minimize the influence of this variable on the estimates of prevalence. It has been established that age can directly influence the prevalence rates in different populations, since it can reflect the cumulative amount of attachment loss during life $(2,12,22,25)$.

It can be hypothesized that the higher prevalence rates found in the present study are related to sample characteristics such as low socioeconomic and educational levels, and limited access to oral health services $(3,6,22,25,26)$. However, the main points of concern from the present study are the differences obtained exclusively by the periodontitis case definition, the use of clinical indicators $\mathrm{PD}$ or $\mathrm{CAL}$ in a single manner or in combination, the number of affected sites required, the threshold values for PD and/or CAL, and the site/surface of measurement.

It must be recognized that use of a universally accepted criteria for periodontitis case definition is decisive, since this lack of uniformity has a great impact on the prevalence rates of periodontitis reported in the present study. Comparing these questions with other studies, periodontal research and therapeutic approaches can be seriously biased.

The present study verified, in relation to definition 1 ( $\geq$ 1 site with $\mathrm{PD} \geq 4 \mathrm{~mm}$ ), a high prevalence of periodontitis $(65.3 \%)$. Although similar to other reports in dental literature $(1,12,25,26)$, the findings showed that this definition appears to be less rigid concerning thresholds of PD and extent requirements of the disease. The application of extent parameters in this definition (cut off point: $30 \%$ of affected sites) led to a higher discrepancy between localized (55.6\%) and generalized (9.7\%) forms of the disease. In addition, the use of PD measurements with no relation to CAL can induce errors in interpretation regarding false periodontal pockets, since PD is well recognized as an indicator of periodontitis with low predictability $(7,9,27)$. For this reason, our judgment is that this definition should be used with caution in periodontal research.

Lower prevalence rates for periodontitis were reported by definition $2(23.8 \%=\mathrm{CAL} \geq 5 \mathrm{~mm}$ at $\geq 4$ sites + one site with $\mathrm{PD} \geq 4 \mathrm{~mm})$, definition $3(16.5 \%=\mathrm{CAL} \geq 6 \mathrm{~mm}$ at $\geq 2$ sites + one site with $\mathrm{PD} \geq 5 \mathrm{~mm}$ ), and definition $5 \mathrm{~b}$ $(13.8 \%$ = interproximal $\mathrm{CAL} \geq 6 \mathrm{~mm}$ at $\geq 2$ sites on different teeth $+\mathrm{PD} \geq 5 \mathrm{~mm}$ at one proximal site - advanced periodontitis). These findings differ from a number of large epidemiologic studies that have used similar definitions $(9,13,16,21,28)$.

In this manner, it can be inferred that these definitions adopt rigid cut off points for PD and CAL and, as a result, can underestimate the real prevalence of periodontitis within the populations. In addition, similarities in the prevalence rates reported by these definitions may be explained by the 1-mm difference between the thresholds for PD and CAL within the criteria. Another important issue is the similar extent indicators applied by these definitions, although a more rigid parameter was adopted by definition 3. Definition $5 \mathrm{~b}$ is quite similar to definition 3 , but the requirement of attachment loss occurs at interproximal sites. Consequently, differences in prevalence rates reported by definitions 3 and $5 \mathrm{~b}$ can be related to the strictness of definition $5 b$.

Definitions 4 and 5a, reporting prevalence rates of $38.6 \%$ and $41.2 \%$, respectively, proved to be similar and resulted in prevalence rates which were more compatible with previous reports $(11,18,26,29)$. It is important to highlight that definitions $5 \mathrm{a}$ and $5 \mathrm{~b}$ are more prone to avoid errors from attachment loss measurements due to reasons other than periodontitis, as they employ interproximal measurements. Finally, a prevalence rate of $41.2 \%$ was reported by definition $5 \mathrm{a}$ (interproximal CAL $\geq 4 \mathrm{~mm}$ at $\geq 2$ sites, not on the same tooth, proposed by the Periodontal Disease Surveillance Workgroup of the Division of Oral Health at the Center for Disease Control and Prevention - CDC) (15). It is important to note that this definition was proposed to define moderate periodontitis. To defined advanced periodontitis, the Periodontal Disease Surveillance Workgroup has proposed interproximal attachment loss $\geq$ $6 \mathrm{~mm}$ at $\geq 2$ sites, not on the same tooth + one site with interproximal $\mathrm{PD} \geq 5 \mathrm{~mm}$. As a result, the authors of this study believe that definition $5 \mathrm{~b}$ is too robust and can exclude real cases of periodontitis (15). 
Many authors have recognized the cut off point of 30\% of the affected sites as adequate in differentiating localized from generalized forms of periodontitis $(9,30,31)$. When analyzing the extent of periodontitis in the present study, based on these criteria associated with different definitions, findings showed a great variability among definitions concerning extent rates. Although the number of affected sites required by each definition impacts the definition per se, this number did not influence the extent of $30 \%$ adopted in the present study. It was reinforced by findings that demonstrated that subjects under different case definitions were mixed up in the same pattern of extent. This observed variation may reflect the threshold of $\mathrm{PD}$ and/or CAL (higher values for definitions 4 and 5a) and/or threshold values for probing measurements (higher values for definitions 2 and 3). Within these definitions, a lower difference between localized and generalized prevalence rates could be observed. Differences within definition 1 ( $\geq 1$ site with $\mathrm{PD} \geq 4 \mathrm{~mm}$ ) were of great impact (localized $=55.6 \%$, and generalized $=9.7 \%$ ).

The Kappa test presented a satisfactory agreement between definitions 1 and 4 (0.72), 1 and 5a (0.73), 2 and 3 (0.72), 4 and 5a (0.71), and 3 and $5 \mathrm{~b}(0.69)(P<0.001)$. It can be inferred that the satisfactory agreement between definitions 1 and 4, and between definitions 1 and 5a, may be related to the low strictness of definition 1 . It can also be inferred that the good agreement between definitions 4 and $5 \mathrm{a}$, as well as between definitions 3 and $5 \mathrm{~b}$, may be related to similarities of extent and severity parameters of periodontal attachment loss.

Based on the state of the art related to definitions of periodontitis, the authors of the present study considered it reasonable to elect a recently published and well-founded definition that required PD or CAL measurements in interproximal sites (minimizing errors from attachment loss due to reasons other than periodontitis) as well as extent (two sites not on the same tooth) and severity (PD $\geq 5 \mathrm{~mm}$ or $\mathrm{CAL} \geq 4 \mathrm{~mm}$ ) as the gold standard criterion. Therefore, the definition proposed by the CDC Periodontal Disease Surveillance Workgroup (15), and supported by the American Academy of Periodontology, to define moderate periodontitis was selected among the eligible definitions (definition 5a) as the gold standard. The definition proposed by the same group to define severe periodontiits (definition $5 b$ ) was avoided because we share the same opinion as the CDC Workgroup that this definition can exclude real cases of periodontitis for being too robust.

In accordance with the agreement findings, it was observed that definition 4 (18) presented the best SP and PPV in relation to the gold standard which adopted similar requirements. When analyzing the validity of definitions
- that is, their capacity of distinguishing health from periodontitis - it was noted that only definition 4 presented satisfactory values of SP $(88.3,95 \%$ CI 73.5 - 91.2) and PPV (92.9, 95\% CI 78.1 - 95.7). In this manner, criterion 4 showed higher capacity of correctly identifying periodontally healthy individuals as well as those with periodontitis.

One important topic related to the main theme of the present study is related to association studies. Several studies of the last decade have associated periodontal status to systemic conditions, such as cardiovascular diseases, pulmonary disorders, and adverse pregnancy outcomes (29,32-36). A great number of studies, showing controversial findings, highlighted that periodontal definition criteria strongly influenced the risk estimates of the associations under investigation $(14,35)$. As such studies have a great audience inside and outside the dental field, and if the results are really affected by the periodontitis definition used, the adoption of a universal standard definition is crucial. Beck et al. (33) stated that a periodontitis definition may include reliable extent and severity indicators of attachment loss. Efforts should be directed towards standardizing periodontitis definitions in these types of studies.

It was therefore concluded that different case definitions can have a great impact on the prevalence and extent rates of periodontitis. In this manner, it can influence the results and associations presented in studies as well as over or underestimate the real need for periodontal treatment. Hence, the use of more valid criteria, such as definition 4 and $5 \mathrm{a}$, for the standardization of periodontitis case definitions in periodontal research, is of utmost importance.

\section{References}

1. Baelum V, Fejerskov O, Karring T (1986) Oral hygiene, gingivitis and periodontal breakdown in adult Tanzanians. J Periodontol Res 21, 221-232.

2. Brown LJ, Oliver RC, Löe H (1990) Evaluating periodontal status of US employed adults. J Am Dent Assoc 121, 226-232.

3. Horning GM, Hatch CL, Lutskus J (1990) The prevalence of periodontitis in a military treatment population. J Am Dent Assoc 121, 616-622

4. Diamanti-Kipioti A, Papapanou PN, MoraitakiTsami A, Lindhe J, Mitsis F (1993) Comparative estimation of periodontal conditions by means of different index systems. J Clin Periodontol 20, 656661.

5. Burt BA (1996) Epidemiology of periodontal diseases (position paper). J Periodontol 67, 935-945.

6. Borrel LN, Papapanou PN (2005) Analytical 
epidemiology of periodontitis. J Clin Periodontol 32, suppl 6, 210-213.

7. Kingman A, Albandar JM (2002) Methodological aspects of epidemiological studies of periodontal diseases. Periodontol 2000 29, 11-30.

8. Albandar JM, Tiinoco EMB (2002) Global epidemiology of periodontal diseases in children and young persons. Periodontol 2000 29, 153-176.

9. Research, Science and Therapy Committee of the American Academy of Periodontology (2005) Epidemiology of periodontal disease (position paper). J Periodontol 76, 1406-1419.

10. Tonetti MS, Claffey N (2005) Advances in the progression of periodontitis and proposal of definitions of a periodontitis case and disease progression for use in risk factor research. J Clin Periodontol 32, Suppl 6, 210-213.

11. Bourgeois D, Bouchard P, Mattout C (2007) Epidemiology of periodontal status in dentate adults in France, 2002-2003. J Periodontal Res 42, 219227.

12. Susin C, Valle P, Oppermann RV, Haugejorden O, Albandar JM (2005) Occurence and risk indicators of increased probing depth in an adult Brazilian population. J Periodontol 32, 123-129.

13. Holmlund A, Gunnar H, Lind L (2006) Severity of periodontal disease and number of remaining teeth are related to the prevalence of myocardial infarction and hypertension in a study based on 4,254 subjects. J Periodontol 77, 1173-1178.

14. Andriankaja O M, Genco RJ, Dorn J, Dmochowski J, Hovey K, Falkner KL, Scannapieco F, Trevisan M (2006) The use of different measurements and definitions of periodontal disease in the study of the association between periodontal disease and risk of myocardial infarction. J Periodontol 77, 1067-1073.

15. Page RC, Eke PI (2007) Case definitions for use in population-based surveillance of periodontitis. J Periodontol 78, 1387-1399.

16. Borrel LN, Burt BA, Taylor GW (2005) Prevalence and trends in periodontitis in the USA: the NHANES, 1988 to 2000. J Dent Res 84, 924-930.

17. Beck JD, Koch GG, Rozier GR, Tudor GE (1990) Prevalence and risk indicators for periodontal attachment loss in a population of older communitydwelling blacks and whites. J Periodontol 61, 521528.

18. López NJ, Smith PC, Gutierrez J (2002) Periodontal therapy may reduce the risk of preterm low birth weight in women with periodontal disease: a randomized controlled trial. J Periodontol 73, 911-
924.

19. Hujoel PP, Lydon-Rochelle M, Robertson PB, Aguila MA (2006) Cessation of periodontal care during pregnancy: effect on infant birthweight. Eur J Oral Sci 114, 2-7.

20. Beck JD, Löe H. (1993) Epidemiological principles in studying periodontal diseases. Periodontol 2000 2, 34-45.

21. Machtei EE, Christersson LA, Grossi SG, Dunford R, Zambon JJ, Genco RJ (1992) Clinical criteria for the definition of "established periodontitis". J Periodontol 63, 206-214.

22. Papapanou PN (1996) Periodontal diseases: epidemiology. Ann Periodontol1, 1-36.

23. Costa FO, Cota LOM, Costa JE, Pordeus IA (2007) Periodontal disease progression among young subjects with no preventive dental care: a 52-month follow-up study. J Periodontol 78, 198-203.

24. Bragamian RA, Farghaly MM, Lopatin D, Sowers M, Syed SA, Pomerville JL (1993) Periodontal disease in an Amish population. J Clin Periodontol 20, 269-272.

25. Albandar JM, Brunelle JA, Kingman A (1999) Destructive periodontal disease in adults 30 years of age and older in the United States, 1988-1994. J Periodontol 70, 13-29.

26. Papapanou PN, Wennstrom JL (1990) A 10-year retrospective study of periodontal disease progression: clinical characteristics of subjects with pronounced and minimal disease development. J Clin Periodontol17, 78-84.

27. Greenstein G (1997) Contemporary interpretation of probing depths assessments: diagnostic and therapeutic implications. A literature review. J Periodontol 68, 1194-1205.

28. Moore WEC, Holderman LV, Smibert RM, Hash DE, Burmeister JA, Ranney RR (1982) Bacteriology of severe periodontitis in young adult humans. Infect Immun 38, 1137-1148.

29. Siqueira FM, Cota LOM, Costa JE, Haddad JP, Lana AMQ, Costa FO (2007) Intraterine growth restriction low birth weight, and preterm birth: adverse pregnancy outcomes and their association with maternal periodontitis. J Periodontol 78, 22662276.

30. Ismail AI, Morrison EC, Burt BA, Cafesse RG, Kavanagh MT (1990) Natural history of periodontal disease in adults: findings from the Tacumseh periodontal disease study, 1959-87. J Dent Res 69, 430-435.

31. Locker D, Leake JL (1993) Periodontal attachment 
loss in independently living older adults in Ontario, Canada. J Public Health Dent 53, 6-11.

32. Offenbacher S, Katz V, Fertik G, Collins J, Boyd D, Maynor G, Mckaig R, Beck J (1996) Periodontal infection as a possible risk factor for preterm low birth weight. J Periodontol 67, 1103-1113.

33. Beck JD, Pankow J, Tyroler HA, Offenbacher S (1999) Dental infections and atherosclerosis. Am Heart J 138, S528-S533.

34. Scannapieco FA, Bush RB, Paju S (2003) Association between periodontal disease and risk for atherosclerosis, cardiovascular disease, and stroke.
A systematic review. Ann Periodontol 8, 38-53.

35. Gomes-Filho IS, Cruz SS, Rezende EJC, dos Santos CAST, Soledade KR, Magalhães MA, de Azevedo ACO, Trindade SC, Passos J, de S Cerqueira EMM (2007) Exposure measurement in the association between periodontal disease and prematury/low birth weight. J Clin Periodontol 34, 957-963.

36. Siqueira FM, Cota LOM, Costa JE, Haddad JP, Lana AMQ, Costa FO (2008) Maternal periodontitis as a potential risk variable for preeclampsia: a casecontrol study. J Periodontol 79, 207-215. 